RESEARCH REPORT

\title{
VIDEO MODELING FOR CHILDREN WITH AS- PERGER SYNDROME OR HIGH FUNCTIONING AUTISM
}

\begin{abstract}
A multiple case study was conducted over the duration of six months to assess the effectiveness of video modeling intervention in teaching social behaviors. A group of 20 children with Asperger Syndrome or High Functioning Au-tism were selected from mainstream public school. Each child watched a videotape demonstrating a targeted be-havior by a typically developing peer or a video of them-selves modeling the appropriate behavior. The child was then asked to engage in a social situation demanding the use of previously taught behavior. A special education teacher, classroom teacher, and speech-language pathologist rated the child's interaction and use of target-ed behaviors. Videos were used to modify, teach or shape a target behavior for the child to imitate and learn. For the purpose of this study, three specific behaviors were taught: teaching compliment giving, initiations, maintain-ing conversations, and learning and obeying classroom rules. Results of this study indicated that video modeling is an effective intervention method in teaching social behav-iors to children on the Autism Spectrum. All participants showed an increased use of targeted social behaviors and also attempted to generate behaviors regardless of target-ed stimuli. Further research in using adults as models and targeting various social behaviors is warranted.
\end{abstract}

\section{Keywords}

Autism, Asperger syndrome, High-Functioning Autism, Social Interaction, Video Model, Social Behaviors

\section{Humaira Hussain}

Clinical Speech and Language Pathologist

Institute of Physical Medicine and Rehabilitation

Dow University of Health Sciences humairahussain.slp@gmail.com

[Hussain H. Video Modeling for Children with Asperger Syndrome or High Functioning Autism. Pak. j. rehabil. $2015 ; 5(1): 37-41]$ 


\section{INTRODUCTION}

Asperger Syndrome (AS) is a developmental disorder which is classified under the Au-tism Spectrum Disorders. Asperger's is clas-sified as a neurological condition which causes a degree of impairment in social lan-guage and communication skills, and repeti-tive patterns of behavior. Previous research has suggested brain abnormalities as the cause of AS. Several Advanced Brain Imag-ing techniques have revealed structural and functional differences in specific regions of the brain versus a normal brain'. These de-fects are most likely caused by abnormal migration of embryonic cells during fetal development that affects the wiring of the brain ${ }^{2}$. Children with Asperger Syndrome vary in skills and impairments as compared to children with Autism. Most of the lan-guage impairments associated with Asper-ger syndrome is seen in pragmatics and so-cial communication. Individuals with AS not only develop early language skills, they also have above average or average IQ level, high level of vocabulary, well developed syntax and phonology, and formal speech patterns ${ }^{3}$. Furthermore, individuals with AS have repetitive patterns of behaviors, so-cially and emotionally inappropriate behav-iors, the inability to interact with peers, un-coordinated motor movements, and prob-lems with non-verbal communication or dif-ficulty understanding supra-segmental fac-tors ${ }^{4,5}$.

\section{Overview of Asperger Syndrome}

Asperger Syndrome was first recognized by Viennese pediatrician Hans Asperger in the 1940's. Per his observations, there were some children especially males with normal intelligence and typical language develop-ment; however had difficulty in social and communication skills. Some professionals working with children with AS felt it is was a milder version of Autism; however recent studies have shown that there are specific characteristics that distinguish the two dis-orders. For instance, children with Asper-ger's are often observed as wanting to in-teract with peers; however express signifi-cant difficulty in understanding how to. They seem to have the knowledge and the skills to communicate; however lack the in-structions of how to socially interact. Some children with AS have demonstrated poor and limited eye contact, and are often seen unengaged in conversations. Many clini-cians refer to children with AS as being aloof or disengaged with the world around themb. Furthermore, it has been observed that children with AS have difficulty under-standing some key concepts of communica-tion such as use of gestures, empathy, un-derstanding abstract concepts, and lack of interest in various topics. Also, some chil-dren with AS have intense obsessions and become focused on one topic and are keen to maintain the same topic of conversa-tions ${ }^{7}$.

Additionally, the major difference between children with Autism and Asperger syn-drome is that children with AS do not have a speech and language delay. In fact, most children with AS have above normal intelli-gence and very good language skills; how-ever lack components of expression and prosodic features in speech ${ }^{8}$. Furthermore, children with AS, usually have unusual speech patterns with an absence of rhyth-mic pattern; for instance, volume and pitch are seldom increased. Also, there is a lack of inflection in speech pattern and speech may sound awkward to an untrained listener. Similarly, children with AS have a very con-crete understanding of language, struggle with turn-taking during conversations and have difficulty understanding humor and iron?.

\section{INTERVENTION APPROACH - VIDEO MODELING}

Video modeling is a technique used in this research in order to teach social skills to children with AS and High-Functioning Au-tism (HFA). More specifically, the child with AS or HFA, was appointed to watch a series of videos which modeled a targeted behav-ior. The target behavior was decided amongst the classroom teacher and the Speech-Language Pathologist (SLP) as a be-havior that the child in question lacks ${ }^{10}$. Vid-eo models were used to illustrate charac-ters giving compliments to their peers to teach a specific social skill to the child with AS or HFA. Using this approach, the video shown to the child is used to modify, teach, or shape target behaviors for the child to imitate and learn? ${ }^{7}$. There are behaviors for which video modeling can be used, such as: teaching compliment giving, initiations, maintaining conversations, and learning and obeying classroom rules. There has been previously done research in this area, how-ever video modeling was specifically used to increase conversational skills, perspective taking, play sequences, and social initiations in children with AS and HFA ${ }^{11}$. This study on the contrary was used to teach specific so-cial behaviors to a group of children with either AS or HFA.

\section{METHODS}

In this study, a group of 20 children, aged 5; 2-9; 6 with a diagnosis of Asperger's Syn-drome or High Functioning Autism under-went speech-language therapy for duration of 6-months. Children were of mainstream public school and were all receiving special education and speech therapy services through both a push-in and pull-out therapy approach. Children belonged to an upper-middle class background and were of mixed nationalities. Primary language spoken at home and instructed in school was English. All 10 children watched videos of a targeted behavior being modeled by a same age group peer. The goal of the study was to assess for efficacy of video modeling in teaching targeted social behaviors to chil-dren with AS or HFA. Video modeling was applied to three different social situations: compliment-giving, joining and maintaining a 
conversation, and learning classroom rules.

\section{VIDEO MODELING AS A TOOL FOR COMPLI- MENT-GIVING BEHAVIORS}

In this study, several phrases were deter-mined as compliment-giving behaviors. Three types of sentence structures were accepted as a compliment from the child. The first sentence structure included phrases such as "Nice," or "Cool"; and the second sentence structure consisted of phrases such as: "I like your shoes," or the carrier phrase "I like" followed by a posses-sive adjective. Finally, the last phrase was constructed to give compliments such as: "You have/ or made" followed by the word describing the item in possession. These structures were based on the most com-monly heard and used phrases in preschool settings. Any sentences which did not fit the grammatical structure of the phrases de-scribed above, was marked as an "l" for ini-tiation or an "R" for response compliment. The compliments marked with an "I" or "R" were presented and rated by a parent, classroom teacher, and a special education teacher who determined if the utterance was indeed a compliment from the child to his peer. It was concluded that children in the experimental group were able to ac-quire more compliments and initiations in their interactions with peers through the use of video modeling. Additionally, the positive reinforcement given by teachers and parents in the form of rewards and verbal prompts also strengthened this be-havior.

\section{VIDEO MODELING AS A TOOL FOR JOIN-ING IN AND MAINTAINING CONVERSA-TIONS}

A second manner in which video modeling was conducted was through a screening of three short videos to school-age children with AS. The videos used similar-aged peers using target behaviors in a natural way for the student with AS/HFA to view. Some of the targeted behaviors included joining in and maintaining conversations: Joining in was defined by the student as actively initi-ating or participating in conversation or play with a peer, and maintaining conversations consisted of the student actively contrib-uting during a reciprocal conversation with a peer or group ${ }^{12}$. Some examples of join-ing in behaviors include: requesting atten-tion or acknowledgement (i.e. "hey"), ver-bally initiating a new idea, borrowing or lending toys, or participating in any type of organized group game (i.e. tag, hide-and-seek). Examples of maintaining conversa-tions include: making "small talk," playing next to a peer, providing a comment within three seconds of a peer's utterance, an-swering a peer's question or confirming or clarifying a question or comment from a peer.

During the intervention phase, the students watched video models prior to the targeted social setting which was either the play-ground during recess, the cafeteria, or dur-ing any group class- room activities. If a stu-dent was having difficulty using the target-ed behaviors, additional teacher prompting was added immediately before the targeted social situation (i.e. during the beginning of recess) ${ }^{13}$. For some of the students, even after using the target behaviors (joining in, and maintaining conversation) effectively, some of their peers continued to ignore their communicative intents and therefore the use of child confederates was imple-mented. After the initial intervention phase, each of the student's intervention was faded over a two week time period to measure whether or not the targeted skills was maintained or generalized ${ }^{14}$. At the end of the two week mark, all of the partic-ipants demonstrated improved rates of tar-geted behaviors compared to their baseline performance. Based on this study, it can be concluded that video modeling may lead to faster acquisition of target behaviors and higher chances of generalization when teaching social skills to children with HFA/AS.

\section{USE OF VIDEO MODELING TO TEACH CLASSROOM RULES}

Finally, video modeling was assessed as an intervention technique through the use of teaching classroom rules. Clinicians exam-ined effectiveness of video modeling for two classroom students who were taught to remember and learn classroom rules and eventually obey them. Prior to gathering data, a pilot experiment was conducted in the classroom. Three rules were designed in collaboration with the classroom teacher: the first was to stay in your assigned area, the second was to do what the teacher says, and the third was to keep your hands to yourself. The students were all made aware of these rules at the beginning of the year and there was a sign posted on the wall with the rules being stated. For the purpose of this pilot experiment, if a child did not follow the rule, the teacher was trained to explicitly inform the child of what they are doing incorrectly and further mod-el the appropriate behavior; in this case fol-lowing the predesigned classroom rule. Further, each student was asked to go into a separate room and was asked to say the three rules. When the participant could ac-curately recite all three rules, she was al-lowed to rejoin her class $^{15,4}$.

During data collection of the actual experi-ment the child was asked to recite the three rules before the video-taping began. These sessions were continued until the student could accurately say all three of the rules. Each of these children was shown the vide-os of themselves disobeying the rule. The student was asked if they were breaking the rule, and what they could do to prevent this behavior. Once they acknowledged what they could do differently, they were shown a section of their tape in which the rule was not being broken and were then verbally praised by the classroom teacher. Same methodology was used for all three rules until 
the rule was no longer broken. This went on during the $2^{\text {nd }}, 4^{\text {th }}, 8^{\text {th }}$, and $12^{\text {th }}$ week. If the student accurately recalled a rule, they were scored as accurate, and if they recited a rule incorrectly, it was scored as incorrect. Once intervention was with-drawn video self-modeling was found to be useful in teaching and maintaining class-room rules for an average duration of 12 weeks.

\section{USE OF MULTIPLE-CASE STUDY IN VIDEO-MODELING}

Video Modeling can be used as an interven-tion technique for children with Asperger Syndrome or High Functioning Autism. This approach includes various methodologies enabling the clinician to be flexible with the approach they take; modeling of behaviors video models of same-aged peers, or self-modeling. Video modeling can be used to address several challenging behaviors such as compliment-giving, initiations, maintain-ing conversations, and learning and obeying classroom rules. In all three sub-experiments, multiple case studies were used involving a minimum of 6-8 children per experimental group. Since every child with Asperger Syndrome and High-Functioning Autism differs in their needs, the use of a multiple-case study design was effective because it took each child's needs into perspective ${ }^{15}$. It can also be validated that using a multiple-case study design to observe progress with video modeling was effective because using video modeling in a multiple-case study compels the research-ers to consider many factors to obtain col-lectible data. Therefore, in using a multiple-case study design, clinician was able to ef-fectively apply the intervention in a natural-istic and practical manner.

Since multiple sources of reliable data will validate the effectiveness of video model-ing, further use of such techniques with a larger group of children with Asperger Syn-drome of High Functioning Autism will yield better results. Video modeling should be implemented and compared with other techniques when deciding an approach to teach social skills to children with Asperger Syndrome and High-Functioning Autism ${ }^{16}$. Although there are many benefits to using video modeling as an ideal intervention ap-proach, one of the challenges that may arise, includes: spending extensive time ed-iting videos to present an appropriate mod-el of behavior ${ }^{3}$. This may not be suitable for therapists working with a large case load as the time consumed on editing videos might not be ideal. Also, the studies in discussion used peers as models of target behaviors; and for some school districts and therapists, having peers model target behaviors may not be suitable as some parents and peers are not cooperative. In this case, the use of adults as models would be implemented; however, there are currently no studies that have used adults as models for target behaviors in intervening for children with Asperger's Syndrome. There are however, several authors of various studies that favor using adults as models as being more effec-tive, because it would reduce the use of prompts and editing process of videos ${ }^{2}$. In conclusion, understanding the challenges faced by therapist in teaching social skills to children with AS/HFA is neither a dry men-tal exercise nor a mandate from the Ameri-can Speech-Language-Hearing Association. As a scientist, it is a privilege and a duty to provide objective insight which might drive treatment strategies and as a clinician, it is a prerogative to artfully incorporate scien-tific findings for the benefit of children on the Autism Spectrum.

\section{REFERENCES}

[1] Park B. Video Modeling Interventions for Individuals with Autism - A Review from 1998 to 2007-.Special Educa-tion Research. 2008;7(1):123

[2] Apple A, Billingsley, F, \& Schwartz, I. . Effects of video modeling alone and with self-management on compliment giving behaviors of children with high-functioning ASD. Journal of Positive Behavior Intervention, (2005); 7(1):33-46.

[3] Tager-Flusberg, H. (1995). Attributing mental states to story characters: a comparison of narratives produced by autistic and mentally retarded individuals. Applied Psycholinguistics, 16, 241-256.

[4] Sperry L. Perceptions of social chal-lenges of adults with autism spectrum disorder. Autism. 2005:9(4):362-376.

[5] Cardon T, Wilcox M. Promoting Imita-tion in Young Children with Autism: A Comparison of Reciprocal Imitation Training and Video Modeling. J Autism Dev Disord. 2010;41 (5):654-666

[6] Baron-Cohen S. Social and pragmatic deficits in autism: Cognitive or affec-tive?. J Autism Dev Disord. 1988; 18(3):379-402

[7] Cardon TA. Technology and the treat-ment of children with autism spectrum disorder. (ed)Switzerland: Spring Inter-national Publishing Switzerland;2014

[8] Bellini S, Akullian J. A Meta-Analysis of Video Modeling and Video Self-Modeling Interventions for Children and Adolescents with Autism Spectrum Disorders. Exceptional Children. 2007;73(3):264-287.

[9] McDowell L, Gutierrez A, Bennett K. Analysis of Live Modeling Plus Prompt-ing and Video Modeling for Teaching Imitation to Children with Autism. Be-havioral Interventions. 2015;30(4):333-351.

[10] Welton E, Vakil S, Carasea C. Strategies for Increasing Positive Social Interac-tions in Children with Autism: A Case Study. TEACHING Exceptional Children. 2004;37(1):40-46

Lang R, Shogren K, Machalicek W, Rispoli, M, \&

[1 1 ] O'Reilly, M.. Video self-modeling to teach classroom rules to two students with aspergers. Research in Autism Spectrum Disorders (2008);(3):483-48

[12] Talbot C. Scott Bellini, Building Social Relation- 
ships: A Systematic Approach to Teaching Social Interaction Skills to Children and Adolescents with Autism Spectrum Disorders and Other Social Difficulties (Textbook Edition, 1st ed.). J Autism Dev Disord. 2008;38(7):1402-1403

[13] National institute of neurological dis-orders and stroke: asperger syndrome. (2010, May 15). Retrieved from http://www.ninds.nih.gov/disorders/asperger/asperger.htm

[14] Tager-Flusberg H. (1996). Brief report: current theory and research on lan-guage and communication in tism. Journal of Autism and Devel- op-mental Disorders, 26, 169-172.

[15] Nikopoulos C, Keenan M. Promoting social initiation in children with autism using video modeling. Behavioral Inter-ventions. 2003;18(2):87-108.

[16] Sansoti F, \& Powell-Smith K. (2008). Using computer-presented social sto-ries and video models to increase the social communication skills of children with high-functioning autism-spectrum disorder. Journal of Positive Behavior Intervention, 10(3), 162-178. 